\title{
O EXPRESSIONISMO E A POÉTICA DO LIXO
}

THE EXPRESSIONISM AND THE POETICS OF WASTE

Olga Kempinska

GCL-UFF

Resumo: A mais violenta das vanguardas artísticas do início do século XX, o expressionismo desafia o discurso totalitário por meio da atualização da ambivalência entre o puro e o impuro característica do regime do sagrado. O presente trabalho busca compreender o sentido do expressionismo na literatura em um diálogo frutífero com as artes visuais. A poética do lixo elaborada em diferentes âmbitos culturais pelos autores tais como Wassily Kandinsky, Czesław Miłosz, Witold Gombrowicz e Nuno Ramos torna-se nesse contexto uma forma de se trazer para o âmbito da arte a preocupação pela vida subjetiva do ser humano ameaçada pelo nivelamento totalitário.

Palavras-chave: expressionismo, totalitarismo, lixo, sagrado.

Abstract: The most violent among the artistic avant-gardes of the early twentieth century, the Expressionism challenges the totalitarian discourse by using the ambivalence between the pure and the impure characteristic of the regime of the sacred. The present article seeks to understand the meaning of expressionism in literature in a fruitful dialogue with the visual arts. The poetics of waste elaborated in diverse cultural domains, by the authors such as Wassily Kandinsky, Czesław Mitosz, Witold Gombrowicz and Nuno Ramos becomes in this context a way of bringing to the scope of art the concern for the subjective life of the human being threatened by totalitarian levelling.

Keywords: Expressionism, Totalitarianism, Waste, Sacred. 
Na ilusão da vida, eis o homem que encontra suas verdades e que as perde, na terra da morte, para voltar, através das guerras, dos gritos, da loucura de justiça e de amor, enfim, da dor, para esta pátria tranquila, em que a própria morte é um silêncio feliz. Eis, ainda...

Albert Camus

O discurso totalitário "é concebido como uma ordem" (GŁOWIŃSKI, 2014, p. 97), dispensando por completo os elementos persuasivos. Seu sujeito é radicalmente não subjetivo e remete a um "depositário do 'correto'” (GŁOWIŃSKI, 2014, p. 98), que abusa das dicotomias claramente delimitadas, e que revela a seu ouvinte passivo uma visão do mundo como conspiração. Tendo percebido muito cedo as ameaças do totalitarismo, as vanguardas artísticas do início do século XX reagiram com violência aos abusos dos sistemas de opressão. Dentre essas respostas, destaca-se o expressionismo, que dialoga com o discurso religioso em busca dos meios da resistência subjetiva. Atualizando o regime do sagrado baseado na ambivalência do puro e do impuro, o expressionismo encontra na poética do lixo um de seus desdobramentos mais significativos.

\section{O expressionismo e o discurso religioso}

O poema "Cabeças", de 1937, encena a multiplicidade subjetiva valorizada no contexto da poética expressionista, a mais violenta de todas as propostas vanguardistas e que possui como uma de suas características importantes a exploração dos recursos subjetivos do ser humano e a desconfiança em relação ao discurso científico:

O homem de três cabeças parou na beira do mato. Nos dois ombros pousaram seus pescoços a má e a boa.

O rosto do meio estava turvado e ele, calado, brilhava como um candelabro de três braços.

O homem escreveu na areia os nomes. A má cabeça sussurrou: Impuro, de coração seco, você ninguém ama.

Mas a boa voltou seu olhar:

- Ah, qual amor carrega mais puro pesar do que a pena de não se ter bastante amado.

Na skraju lasu zatrzymał się człowiek a miał trzy głowy. Na ramionach obu oparły szyje zła głowa i dobra.

Twarz ta pośrodku była zamącona i milczał, błyszcząc jak świecznik trójzębny.

Człowiek wypisał na piasku imiona. Zła głowa wtedy szepnęła: - Nieczysty, serca oschłego, nie kochasz nikogo.

A głowa dobra zwróciła wejrzenie: - Ach, jakaż miłość czystsze nosi brzemię, niż rozpacz, że się nie dosyć kochało. (MIŁOSZ, 2011, p. 111, tradução minha)

Na obra de Czesław Miłosz, que assinala uma forte tendência ao catastrofismo, muito cedo surge a questão da intensa erosão do imaginário religioso, que diz respeito à percepção de "sombras e rachaduras" (TEUSZ, 1999, p. 148) no todo metafísico. Entretanto, são justamente a complexidade e a historicidade desse imaginário que se transformam no âmbito expressionista em contrapesos eficazes ao discurso dicotômico da ciência. Destarte, no poema "Cabeças", que lança mão da forma dialógica, entre "não amar ninguém" e "não ter amado bastante" aparece uma zona fértil de incerteza ética e emocional que se torna o espaço da resistência psíquica do ser humano.

Fazendo parte da primeira fase da produção do poeta polonês, fortemente marcada pela atuação em um grupo expressionista de Vilna 
formado em 1931, o poema apresenta, de fato, algumas características da vanguarda. Inaugurado no século XIX no contexto da discussão acerca das inovações na produção artística, o próprio termo "vanguarda" "conservará suas ressonâncias de militância e combate” (RIOUT, 2014, p. 10) e, de fato, os movimentos vanguardistas insistem na dimensão autocrítica da arte. Assim, a elaboração das unidades materiais da estrutura da obra no próprio fazer artístico torna-se a questão central da arte vanguardista. No bojo das diversas vanguardas do início do século XX, no qual a prática artística costuma coincidir também com a produção do discurso teórico, o expressionismo distingue-se pela relação com a abstração e com a violência. Rejeitando a figuração e subvertendo o sentido do "realismo" - com o qual mantém, no entanto, uma relação de contraponto -, e afirmando a intensidade do medo como a principal emoção da condição humana nos tempos da crise da confiança no progresso e do conhecimento científico, o expressionismo atinge, de fato, os limites da lucidez:

A consequência do pessimismo de Miłosz, sua expressão escatológica são os meios que pela completude do desespero, apagando o caráter provisório da fonte desse pessimismo investem-no com a dignidade de uma visão geral da realidade, importante independentemente de suas origens. Nessa origem casual e ao mesmo tempo na completude do pessimismo de Miłosz talvez resida a fonte das numerosas antíteses, nas quais se articula seu lirismo. (WYKA, 1937, p. 169)

Um intenso conflito formal havia se tornado o núcleo da composição pictórica de Wassily Kandinsky, dispensando a figuração e encontrando sua forma na apresentação do contraste cromático. De fato, mobilizando um imaginário religioso em crise, os primeiros quadros abstracionistas, pintados por Kandinsky na Alemanha, remetem à violência simbólica e às questões escatológicas, evocando "o tema do Juízo Final, um tema frequente nas obras do período anterior à Guerra, paralelamente com outros parecidos: apocalipse, ressureição, destruição e renascimento" (DÜCHTING, 1992, p. 39).

A composição do poema "Cabeças" em duas estrofes atualiza uma estrutura de oposição, evitando, contudo, a simples dicotomia graças a sua irregularidade. Oriundo da decepção existencial, da impressão de uma catástrofe iminente, contestador do realismo e da representação da realidade "exterior", o expressionismo buscou, com efeito, pela encenação do universo subjetivo interior, acentuando "o princípio da expressão de si mesmo e da expressividade em geral” (VAJDA, 1973, p. 47).

"A esmagadora opressão das doutrinas materialistas, que fizeram da vida do universo uma vã e detestável brincadeira, ainda não se dissipou" (KANDINSKY, 2000, p. 28), constatou Kandinsky no texto considerado como o manifesto do expressionismo e do abstracionismo. Escrito em 1910 e publicado em 1912, Do espiritual na arte apresenta o sentido da forma pura proveniente do Oriente e o legado do pensamento da estética do século XVIII, coincidindo com a elaboração da primeira aquarela abstrata e com a determinação da relação entre a produção artística e a necessidade interior. Ao descrever a arte como expressiva, Kandinsky assinala a necessidade de se buscar por "sentimentos mais matizados e ainda sem nome" (KANDINSKY, 2000, p. 28). Dessa maneira, o artista participa do movimento da desconfiança perante o convencionalismo da vida interior típica de todas as vanguardas artísticas do início do século XX, assinalando também a proximidade entre a criatividade e a angústia, comum a todos os artistas expressionistas.

Considerado como um importante precursor 
do expressionismo, o estudo de Wilhelm Worringer Einfühlung und Abstraktion (1908), ao partir da reflexão referente ao âmbito da arquitetura, formula a origem da obra de arte na vontade artística (Kunstwollen), que remete ao conjunto de vivências, no qual pode prevalecer ora a emoção, ora a abstração. A obra de arte constitui, assim, a descarga do impulso da vontade artística. É a tendência à abstração, que, diferentemente da emoção voltada para a afirmação vital e para a ornamentação orgânica, surge da experiência da angústia, ou seja, do intenso pavor suscitado pelo mundo exterior e pelo temor do espaço:

No que tange ao impulso para a abstração, este nasce, segundo Worringer, no solo de uma inquietude, um certo pavor interior do ser humano perante os fenômenos do mundo exterior, material, espacial. Em seu fundamento jaz um temor de perder-se na diversidade dos fenômenos do mundo espacial, o medo do espaço enquanto tal, como algo alheio ao ser humano, Raumschau (Raum - espaço, Schau medo) (sic) temor dele. E desse solo por assim dizer negativo nasce o impulso para se conquistar alguma tranquilidade, para apaziguarse em uma forma espacial simples, transparente, cristalina (cristalizada), na qual se escolhe obviamente as formas relativamente simples

(INGARDEN, 1981, p. 150).

Uma vez que a bibliografia existente sobre a pintura expressionista é muito mais rica e mais consistente do que aquela disponível sobre as obras literárias, extremamente diversificada em seus argumentos e suas conclusões, que não raramente chegam a ser contraditórias, a busca pelos elementos da poética especificamente expressionistas do texto literário, que parecem corresponder ao rigor da pesquisa da interioridade humana e das formas de sua exteriorização, afirmando-se como um "fusionismo entre pensamento científico e espiritualidade" (GONÇALVES, 2002, p. 694) torna-se um grande desafio.

Significativa é nesse sentido a colocação subjetiva no poema expressionista de Miłosz, que abriu a presente discussão. Mais tarde, nos anos 70, enriquecida pela experiência da emigração e da tradução, mas também desgastada pelos horrores totalitários do século XX, a situação intermediária encenada no poema de Miłosz há de se afirmar como característica da dicção poética, como uma imoralidade específica inerente à arte. O poeta sempre está dividido entre o envolvimento e a observação, usando uma "ótica-do-entre" (GOLUBIEWSKI, 2018, p. 38).

Décadas mais tarde das perseguições dos expressionistas, ao criticar o extremo cinismo do ateísmo comunista, Julia Kristeva também assinalará os paradoxos da atitude religiosa: "Cresci na sombra dos ícones e durante muito tempo observei a fé de meu pai, um cristão ortodoxo e seminarista; ele cultivou essa fé, parece-me, como uma revolta íntima contra o ateísmo comunista e como uma religião estética” (KRISTEVA, 2010, p. 209). Diferentemente do impressionismo, com o qual não raramente é confundida, por causa da importância atribuída aos movimentos da subjetividade, a poética expressionista oriunda da preocupação pela salvação da humanidade em meio a uma profunda crise do discurso científico remete à precisão semântica e ao rigor lógico, ou seja, ao "extremo intelectualismo” (WIEDEMAN, 1971, p. 102), que chega por vezes a privilegiar justamente a terminologia científica. Esse uso corresponde, por sua vez, à revolta subjetiva e à tentativa da subversão do discurso da ciência, que passa a ser percebida cada vez mais em termos de um desastroso fracasso do conhecimento humano.

"Nunca conseguirei colocar em um retrato toda a força que existe em uma cabeça” (GENET, 1998, p. 290), afirmou Alberto Giacometti. A força específica da representação de uma cabeça 
humana diz respeito, de fato, a sua articulação inevitável no domínio da ética. Assim, o poema de Miłosz inscreve-se em negativo no contexto das tentativas da invenção literária do drama mental típico da criação da figura do alter-ego, tal como, por exemplo, o de Paul Valéry (1960). Trata-se da investigação da relação entre a imagem do pensamento e a imagem do corpo que discute igualmente com o domínio do testemunho, testis, e com o âmbito auto-referencial da representação do "texto". Figura liminar do discurso filosófico, agente de uma "experiência mental” (REY, 1972, p. 82), o Senhor Teste tornase também o dispositivo monstruoso da análise da relação entre o "eu" e o outro. No poema de Miłosz qualquer dimensão eventualmente científica de uma tal "experiência", vê-se questionada por meio do recurso ao imaginário religioso e da triangulação da relação subjetiva, que ultrapassa um simples diálogo.

\section{O sistema, o lixo e o crime}

Mais novo que Witkacy (Stanisław Ignacy Witkiewicz, 1885-1939), Witold Gombrowicz (19041969) reconhece ter participado junto com ele, e com Bruno Schulz, do protagonismo no Modernismo polonês. Em seu intenso envolvimento com a acentuação da importância da forma, Witkacy foi, contudo, o mais desesperado dos três (Cf. GOMBROWICZ, 1997, p. 17). De fato, exasperado com o vigor do desenvolvimento dos sistemas totalitários, escolhendo o suicídio no dia da invasão soviética da Polônia, o expressionista Witkacy tornou-se o profeta sombrio da "invasão dos mercenários das classes baixas - da indústria cultural imitativa" (JARZĘBSKI, 2014, p. 32).

No último romance de Gombrowicz, intitulado Cosmos e composto no fim do longo e solitário exílio argentino, aparece o cenário de Zakopane, a pitoresca cidade polonesa situada nas montanhas muito importante na vida criativa de Witkacy. Surpreendentemente, o lixo revela-se um elemento relevante da estruturação de um estranho e nefasto sistema, elaborado pelo protagonista narrador e seu companheiro a partir da percepção de um pardal enforcado em um matagal e pendurado em um arame:

Lá, atrás do jardinzinho, atrás da cerca, atrás da estrada, lá era o lugar onde pendia o pardal enforcado no meio de galhos entrelaçados, sobre a terra escura na qual havia pedaços de cartolina, de chapa de aço, de madeira, lá onde as pontas dos pinheiros brilhavam sob o céu estrelado. (GOMBROWICZ, 2007, p. 16)

Ao chocante pardal juntam-se mais tarde uma galinha pendurada e um graveto pendurado, assim como um gato enforcado, para espantosamente culminar em uma morte humana no fim da narrativa.

"O retorno sistemático ao uso da palavra 'caos' e de seus derivados indica uma espécie de obsessão. O caos domina no matagal em volta do pardal enforcado e no quarto de Katasia. Ele está igualmente presente nas ervas daninhas, nas migalhas, no lixo" (TOMASZEWSKI, 1991, p. 422). O sistema, ao mesmo tempo desordenado e compacto, faz, de fato, pensar em um amontoado de lixo. Ao ressaltar a historicidade da sensibilidade humana que concebeu - lixo, que não existia na Idade Média, José Carlos Rodrigues assinala a coincidência entre a expulsão dos mortos e do lixo do espaço da cidade. Assim, o lixo relaciona-se à experiência da sujeira que remete à mistura "de elementos pertencentes a categorias que devem ser mantidas separadas (orgânico e inorgânico, cru e cozido, útil e inútil, privado e público, interior e exterior...)", como também ao deslocamento, a saber, à "conjunção de coisas fora do lugar" (RODRIGUES, 1995, p. 84). 
A interpretação do sentido da sujeira leva, por sua vez, a uma "reflexão sobre a relação entre a ordem e a desordem, ser e não ser, forma e nãoforma, vida e morte" (DOUGLAS, 1966, p. 16). 0 lixo passa, assim, a entrar em uma relação com a experiência do sagrado, sendo este caracterizado como aquilo que foi separado do profano e como contagioso. De fato, as diversas religiões transformam no sagrado aquilo que é rejeitado como sujo: "O sagrado deve ser sempre tratado como contagioso porque relações com ele restringem-se a ser expressas por rituais de separação e demarcação e por crenças no perigo de se cruzar fronteiras proibidas." (DOUGLAS, 1966, p. 35). De certa forma, o lixo pressupõe a existência do sistema, sendo produzido pela ordem como aquilo que foi rejeitado.

De fato, a visão fenomenológica do sagrado, ou seja, a descrição de como este aparece na consciência, como se dá enquanto experiência, remete à ambiguidade da pureza (Cf. CAILLOIS, 1959). A esfera do sagrado é dificilmente descritivel, a não ser como aquilo que se opõe ao profano, correspondendo às emoções do medo e da esperança, e remetendo a diversas proibições. Assim, o homem religioso vive em dois universos complementares, um superficial e o outro profundo, que são rigorosamente definidos em suas respectivas relações. A religião é a estruturação da relação entre as esferas contraditórias do sagrado e do profano, mas o sagrado enquanto tal é algo de que não se pode aproximar sem morrer. O profano é uma espécie de um nada ativo que destrói o sagrado, ou seja, aquilo em termos de que é definido. Uma característica importante do sagrado é sua contagiosidade, uma vez que ela o torna expansivo e dificilmente controlável. A religião determina os ritos que servem à contenção do sagrado.

"O lixo é exatamente isso: uma forma extrema do Mesmo" (RAMOS, 2018, p. 258), observou
Nuno Ramos, cuja obra é marcada por um excesso de material. Em diversas realizações do artista brasileiro, que assinala um dos maiores impasses das vanguardas, a saber, a relação do artista com o material em meio ao fazer artístico, estabelece-se uma conexão obscura entre diversos materiais, por vezes carecentes de identificação. Assim, por exemplo, "a sensação de acúmulo, de fartura transbordando" (MAMMì, 1999, p. 5) torna-se o elemento estruturante da retrospectiva de 1999. Trata-se aqui de um sistema que consiste em um "equilíbrio negativo", cujos elementos "lutam para destruírem-se uns aos outros" (MAMMi, 1997, p. 189).

Vaselina, parafina, tecidos, folhas de ouro, de prata e de palmeira, plásticos, tinta, espelhos, metais, feltro, breu e "materiais diversos" compõem as obras sem título, cuja instabilidade construtiva desafia os hábitos perceptivos do fruidor. $O$ excesso de um material muito heterogêneo, que combina os elementos valiosos com os restos sem serventia, senão abjetos, reveste-se destarte de um caráter assombrosamente nivelador. O uso do ouro em algumas obras traz uma desconfiança quanto aos limites do regime do profano, eventualmente, dos usos da profanação. Quanto à forma, a inexplicável persistência do "todo" evoca um universo tão tenaz quanto desproposital, que desafia a construção do ponto de vista e da distância estética.

Ao destruir a fronteira entre a sociedade e o estado, o sistema totalitário tende a "moldar o indivíduo" (LINZ, 2000, p. 66) no intuito de criar "o novo ser humano", que encontra sua expressão nas narrativas de comportamentos exemplares, marcadas pela superficialidade da abordagem do problema da representação. Cosmos de Gombrowicz, ao trazer em 1965 em suas estruturas a subversão de uma história investigativa, desafia a exemplaridade, pois revela que "não há enigma, mas tão somente a sua aparên- 
cia” (AGAMBEN, 2012, p. 105). A motivação do crime é assim substituída por sua estruturação.

Os protagonistas da narrativa de Gombrowicz, dentre os quais Leon que se expressa em um impressionante e absurdo "neologês" e Lena, que é professora de línguas, descrevem a estranha ocorrência de se matar o pardal como uma travessura, um vandalismo, um sadismo e um infantilismo. O protagonista narrador, que acumula incansavelmente os mais diversos "sinais", tais como as manchas na parede interpretadas como "setas" ou "mapas", ou as partes dos objetos que "apontam" para direções, experimenta em um momento da narrativa a vertiginosa impressão de atravessar um limiar, encontrando-se "do outro lado", a saber, no interior do sistema perverso e absurdo: "Era como se o gato me tivesse transportado para o outro lado da moeda, para outra esfera, onde acontecem mistérios, na esfera dos hieróglifos" (GOMBROWICZ, 2007, p. 80). Dentro desse sistema alucinante, sendo não mais o investigador e sim o criminoso, não mais observando e sim agindo, o protagonista narrador não tardará em se livrar a um ato absurdo e cruel, que grotescamente combina com o todo, enforcando um gato: "Ele ficou pendendo como o pardal e o graveto, completando o quadro" (GOMBROWICZ, 2007, p. 76).

O lixo e a escrita tornam-se nesse contexto metáforas da proliferação das conexões: “(..) senti o cheiro de algo podre, próximo, havia uma pilha de lixo, as chuvas haviam criado um escoadouro perto do muro - troncos, galhos, entuIho, torrões, cascalho - objetos amarelados..." (GOMBROWICZ, 2007, p. 38). A desnorteante multiplicidade das conexões, longe de enriquecer a composição do sistema ou dotá-lo de algum sentido, transforma o conjunto em uma estrutura grotesca e indecifrável, na qual predomina a ação em detrimento da interpretação: "Existe uma dose de realidade, cujo excesso ul- trapassa os limites do suportável" (GOMBROWICZ, 2007, p. 73).

O sistema dos sinais elaborado pelo protagonista narrador, que por momentos lembra o esplendor do caos e o luxo da desordem, não se deixa descrever facilmente, apenas como uma quase-coincidência, uma certa tendência à simetria, um desejo de fazer sentido, tal como em um jogo de palavras cruzadas, ou, ainda, uma obsessão pela completude: "A cada sinal decifrado por acaso, quantos outros poderiam passar despercebidos, escondidos na ordem natural das coisas?" (GOMBROWICZ, 2007, p. 43). O sistema, cuja metáfora é um amontoado de lixo, revela-se, assim, em seus aspectos perversos, sendo ao mesmo tempo o instrumento da decifração e o mecanismo da produção do crime:

Um turbilhão de objetos e situações indefinidas, desconexas, uns e outros detalhes se relacionavam entre si, se completavam, mas em seguida surgiam novas associações, outras direções, era disso que eu vivia, como se não vivesse, um caos, um monte de lixo, uma massa disforme enfiava a mão num saco de lixo e retirava o que fosse, analisando para ver se poderia servir na construção da minha casinha... que, coitadinha, adquiria formas fantásticas... e isso não tinha fim... (GOMBROWICZ, 2007, p. 133)

Surge finalmente também a questão da monstruosa auto-referencialidade do sistema, que encontra na linguagem dos personagens os deslizes semânticos solidários da formação de proposições absurdas, assim como da auto-alimentação e auto-reprodução totalmente descontroladas: "O mel crescia. Começara com a 'lua-de-mel'. Mas agora o 'mel' (graças a Jadeczka) tornava-se cada vez mais 'auto-referente'... cada vez mais asqueroso..." (GOMBROWICZ, 2007, p. 155).

A eficácia da herança vanguardista depois do fim histórico das vanguardas artísticas é incontestável. Ainda que seja difícil confirmar uma 
simples continuidade com o fazer dos artistas dos inícios do século, não é possível negar seu pioneirismo no desfio dos sistemas totalitários em seus aspectos mais nefastos. No caso do expressionismo, que rejeitou a visão científica da interioridade humana buscando por um outro rigor espiritual, o diálogo com o discurso religioso permite a criação da poética de heterogeneidade, que insiste na extrema mescla dos elementos e na violência da construção.

\section{Referências}

AGAMBEN, Giorgio. Ideia da prosa. Trad. J. Barrento. Belo Horizonte: Autêntica, 2012.

CAILLOIS, Roger. Man and the Sacred. Trad. M. Barash. Illinois: The Free Press of Glencoe, 1959.

CAMUS, Albert. $\mathrm{O}$ avesso e o direito. Trad. V. Rumjanek. Rio de Janeiro: Editora Record, 2018.

DOUGLAS, Mary. Pureza e perigo. Trad. M. Siqueira Leite de Barros e Z. Zakia Pinto. São Paulo: Perspectiva, 1966.

DÜCHTING, Hajo. Wassily Kandinsky (18661944). A revolução da pintura. Colônia: Taschen, 1992.

GENET, Jean. "Das Atelier von Alberto Giacometti”. In: Alberto Giacometti. Werke und Schriften. Frankfurt: Schirn Kunsthalle, 1998, pp. 279-293.

GŁOWIŃSKI, Michał. Totalitarian Speech. Frankfurt am Main: Peter Lang, 2014.

GOLUBIEWSKI, Mikołaj. The Persona of Czesław Miłosz. Authorial Poetics, Critical Debates, Reception Games. Berlim: Peter Lang, 2018.

GOMBROWICZ, Witold. Dziennik 1959-1969. Cracóvia: Wydawnictwo Literackie, 1997.

Cosmos. Trad. T. Barcinski e C. A. Sá. São Paulo: Companhia das Letras, 2007.

GONÇALVES, Aguinaldo José. "A estética expressionista na pintura e na literatura”. In: GUINSBURG, Jacob (org.). Expressionismo. São Paulo: Perspectiva, 2002, pp. 679-720.

GUERMAN, Mikhail. Kandinsky. Londres: Park- stone, 2015.

INGARDEN, Roman. Wyktady i dyskusje z estetyki. Varsóvia: PWN, 1981.

JARZĘBSKI, Jerzy. "The Three Versions of Modernity: Witkacy, Schulz, Gombrowicz”. Trad. D. Malcolm. In: Tekstualia 1, 2014, pp. 27-48.

KANDINSKY, Wassily. Do espiritual na arte. Trad. A. Cabral e A. de Pádua Danesi. São Paulo: Martins Fontes, 2000.

KRISTEVA, Julia. Hatred and Forgiveness.

Trad. J. Herman. Nova Iorque: Columbia University Press, 2010.

LINZ, Juan J. Totalitarian and Authoritarian

Regimes. Londres: Lynne Riener, 2000.

MAMMì, Lorenzo. "Nuno Ramos". In: Nuno Ramos. São Paulo: Ática, 1997, pp. 188-189.

MAMMì, Lorenzo. "Noites Brancas". In: RAMOS, Nuno. Noites Brancas. Curitiba: Casa da Imagem, 1999, pp. 5-21.

MIŁOSZ, Czesław. Wiersze wszystkie. Cracóvia: Znak, 2011.

RAMOS, Nuno. Verifique se o mesmo. São Paulo: Todavia, 2019.

REY, Alain. "Monsieur Teste de haut en bas". In: Poétique 9, 1972, pp. 80-88.

RIOUT, Denys. "Vanguardas e rupturas". In: LICHTENSTEIN, Jacqueline (org.). A pintura. Vol. 14. Trad. M. Costa. São Paulo: Editora 34, 2014, pp. 9-16.

RODRIGUES, José Carlos. Higiene e ilusão. O lixo como invento social. Rio de Janeiro: NAU, 1995.

TEUSZ, Leszek. "Erozja wyobraźni religijnej we współczesnej kulturze”. In: Sztuka i filosofia. Varsóvia: SCHOLAR, 1999, pp. 143-162.

TOMASZEWSKI, Marek. "La formation de la réalité dans la Pornogrphie et Cosmos de Gombrowicz". Trad. E. Amiet. In: Révue des études slaves 63, 1991, pp. 419-428.

VAJDA, György M. "Outline of the Philosophic Backgrounds of Expressionism”. Trad. L. Brust. In: WEISSTEIN. Ulrich. Expressionism as an inter- 
national literary Phenomenon. Amsterdam: John Benjamins Publishing Compagny, 1973, pp. 45-58.

VALÉRY, Paul. Euvres completes II. Paris: Gallimard, 1960.

WIEDEMAN, Lyris. "O expressionismo em A paixão segundo G.H.”. In: Letras de Hoje 6, 1971, pp. 88-107.

WYKA. Kazimierz. Rzecz wyobraźni. Disponível em: https://wolnelektury.pl/katalog/ lektura/wyka-rzecz-wyobrazni/ último acesso em 25 de abril de 2020.

\section{Olga Kempinska}

Possui graduação em Filologia Românica - Uniwersytet Jagiellonski (Polônia, 1999), mestrado em Filologia Românica pela mesma universidade, com bolsa em Katholieke Universiteit Leuven (Bélgica), e doutorado em História Social da Cultura pela Pontifícia Universidade Católica do Rio de Janeiro (2008). Desde 2010 é professora 40h DE de Teoria da Literatura da Universidade Federal Fluminense (Departamento de Ciências da Linguagem). Tem experiência na área de Letras, com ênfase em Teoria da Literatura, atuando principalmente nos seguintes temas: estética da recepção, relação entre mímesis e emoções, e poéticas do multilinguismo. 